\title{
Corrigendum to "Caffeoylquinic Acid-Rich Extract of Aster glehni F. Schmidt Ameliorates Nonalcoholic Fatty Liver through the Regulation of PPAR $\delta$ and Adiponectin in ApoE KO Mice”
}

\author{
Yong-Jik Lee (D), ${ }^{1}$ Yoo-Na Jang, ${ }^{1}$ Yoon-Mi Han, ${ }^{1,2}$ Hyun-Min Kim, ${ }^{1,2}$ Jong-Min Jeong (D), ${ }^{1,2}$

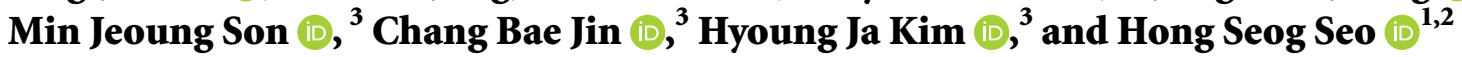 \\ ${ }^{1}$ Cardiovascular Center, Korea University, Guro Hospital, 148 Gurodong-ro, Guro-gu, Seoul 08308, Republic of Korea \\ ${ }^{2}$ Department of Medical Science, Korea University College of Medicine (BK21 Plus KUMS Graduate Program), \\ Main Building 6F Room 655, 73 Inchon-ro (Anam-dong 5-ga), Seongbuk-gu, Seoul 136-705, Republic of Korea \\ ${ }^{3}$ Molecular Recognition Research Center, Materials and Life Science Research Division, Korea Institute of Science and Technology, \\ Hwarangno 14 Gil 5, Seoul 136-791, Republic of Korea
}

Correspondence should be addressed to Hyoung Ja Kim; khj@kist.re.kr and Hong Seog Seo; mdhsseo@unitel.co.kr

Received 2 September 2019; Accepted 11 September 2019; Published 23 October 2019

Copyright (c) 2019 Yong-Jik Lee et al. This is an open access article distributed under the Creative Commons Attribution License, which permits unrestricted use, distribution, and reproduction in any medium, provided the original work is properly cited.

In the article titled "Caffeoylquinic Acid-Rich Extract of Aster glehni F. Schmidt Ameliorates Nonalcoholic Fatty Liver through the Regulation of PPAR $\delta$ and Adiponectin in ApoE KO Mice" [1], the Korea University Guro Hospital grant number should be corrected from O1600121 to O1700571. The Acknowledgments section should be corrected as follows.

This research was supported by an intramural grant from the Korea Institute of Science and Technology (2E26990), a grant from the National Research Foundation of Korea (NRF2016R1A2B3013825), a Korea University grant, a Korea University Guro Hospital Grant (O1700571), and a grant from BK21 Plus Korea University Medical Science Graduate Program. The authors thank Yoon Namkung for proofreading the manuscript and Tae Woo Jung for helping in experimental preparation.

\section{Reference}

[1] Y.-J. Lee, Y.-N. Jang, Y.-M. Han et al., “Caffeoylquinic acid-rich extract of Aster glehni F. Schmidt ameliorates nonalcoholic fatty liver through the regulation of PPAR $\delta$ and adiponectin in ApoE KO Mice," PPAR Research, vol. 2017, Article ID 3912567, pp. 1-19, 2017. 


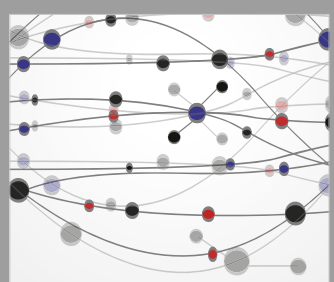

The Scientific World Journal
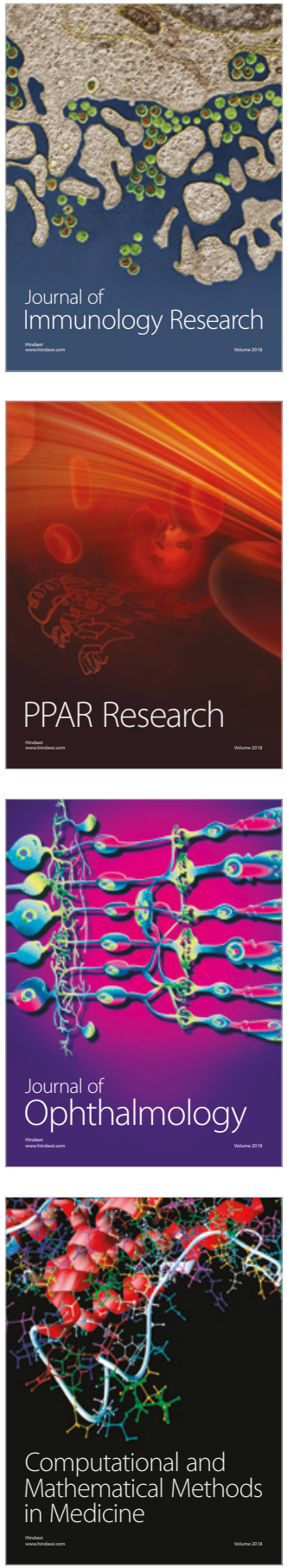

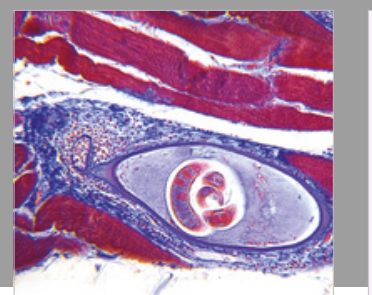

Gastroenterology Research and Practice

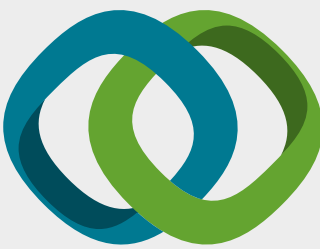

\section{Hindawi}

Submit your manuscripts at

www.hindawi.com
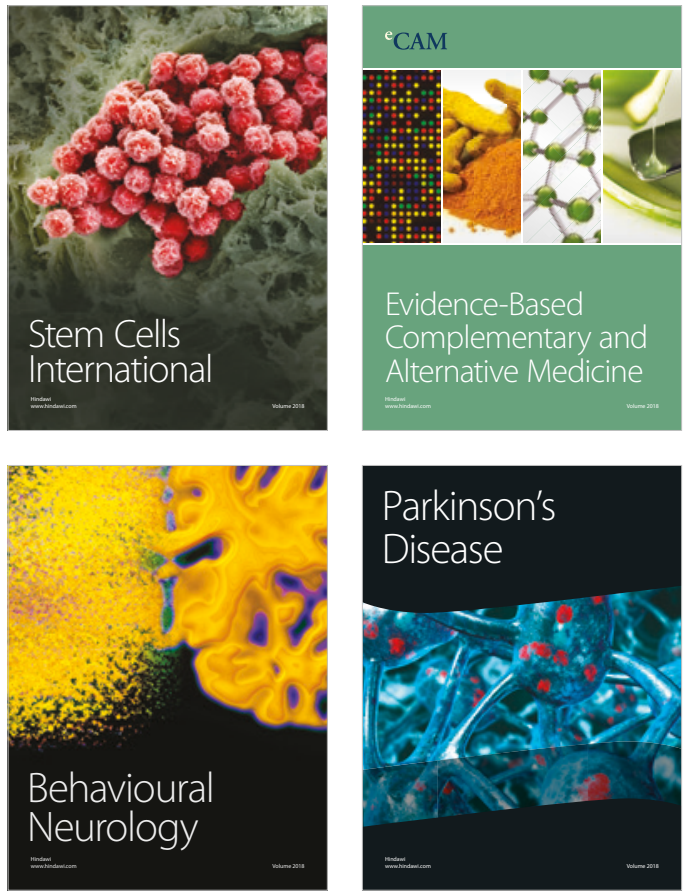

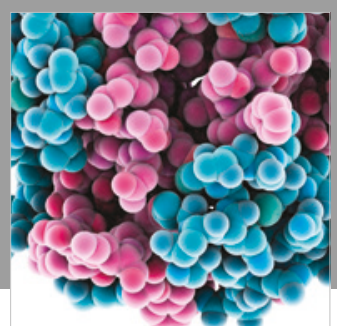

ournal of

Diabetes Research

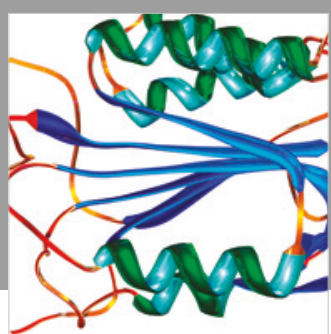

Disease Markers
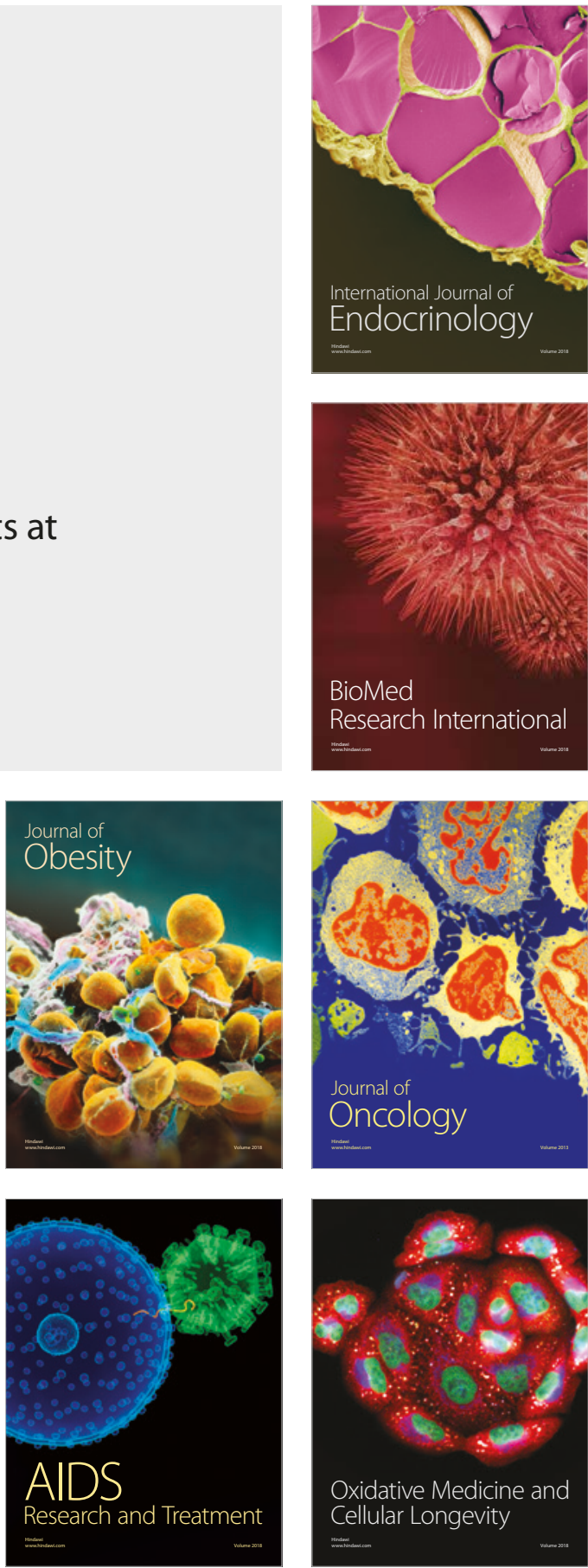